\title{
Nematoides gastrintestinais e Cryptosporidium sp. em avestruzes e fatores associados à infecção no Polo Regional do Paraguaçu, Estado da Bahia
}

\author{
Gastrointestinal nematodes and "Cryptosporidium" sp. in ostriches and factors \\ associated with infection in the Regional Pole of Paraguaçú, State of Bahia
}

\author{
OLIVEIRA, Alex Aguiar de ${ }^{1 *} ;$ BORGES, Simone Lopes ${ }^{2} ;$ JULIÃO, Fred da Silva ${ }^{3}$; \\ SILVA, Ademilton ${ }^{4}$; SOUZA, Verena Maria Mendes de ${ }^{5}$; SILVEIRA, Roberta Xavier \\ $\mathrm{da}^{4}$; TEIXEIRA, Márcia Cristina Aquino ${ }^{6}$; ALMEIDA, Maria Angela Ornelas de ${ }^{7}$
}

\footnotetext{
${ }^{1}$ Universidade Federal da Bahia, Escola de Medicina Veterinária e Zootecnia, Salvador, Bahia, Brasil.

${ }^{2}$ Universidade Federal da Bahia, Escola de Medicina Veterinária e Zootecnia, Departamento de Patologia e Clínicas, Salvador, Bahia, Brasil.

${ }^{3}$ Fundação Oswaldo Cruz, Centro de Pesquisas Gonçalo Moniz, Salvador, Bahia, Brasil.

${ }^{4}$ Universidade Federal da Bahia, Hospital de Medicina Veterinária, Laboratório de Diagnóstico das Parasitoses dos Animais, Salvador, Bahia, Brasil.

${ }^{5}$ Agência de Defesa Agropecuária do Estado da Bahia, Salvador, Bahia, Brasil.

${ }^{6}$ Universidade Federal da Bahia, Faculdade de Farmácia, Salvador, Bahia, Brasil.

*Endereço para correspondência aaoliveiravet@gmail.com.
}

\section{RESUMO}

Os parasitos são responsáveis por prejuízos econômicos na estrutiocultura, visto reduzirem a produção. Para determinar a frequência de nematoides gastrintestinais e de Cryptosporidium sp., em avestruzes, bem como os fatores associados a transmissão, foram colhidas amostras de fezes de 342 avestruzes, dos quais 188 eram adultos e 154 jovens, criados em sete plantéis no Polo Regional do Paraguaçu, para a contagem de ovos por grama de fezes, identificação de larvas de terceiro estádio de nematoides e de oocistos de Cryptosporidium sp. Os dados relacionados aos animais e ao ambiente foram obtidos por meio de visita às propriedades e entrevistas com os produtores. A associação entre a carga parasitária e às variáveis de manejo dos animais foi analisada pelo teste Qui-quadrado e por Razão de $O d d s$, com intervalo de confiança de 95\%. Em todos os plantéis, foram encontradas aves infectadas. Em 88,3\% das amostras de fezes, foram detectados ovos de nematoides gastrointestinal, e, em 18,8\%, oocistos de Cryptosporidium sp. Larvas de Libyostrongylus dentatus (98\%), L.douglassii (2\%) e Codiostomum sp. (2\%) foram identificadas nas coproculturas. Fatores ambientais e de manejo estão associados com risco de enteroparasitos em criações de avestruz. As aves mantidas em piquetes de topografia acidentada, na ausência de outros animais ou que recebiam água procedente de poços ou cisternas, apresentavam menores chances de infecção por nematoides, enquanto para o gênero Cryptosporidium, as criações em áreas planas, com presença de outros animais nos piquetes e o fornecimento da água do rio aumentam as chances (2,7 vezes) de infecção.

Palavras-chaves: aves, coccídio, parasitos, ratitas, Strongylida, Struthio camelus.

\section{SUMMARY}

The parasites are responsible for economic losses in the ostrich, by reducing the production and productivity. To determine the frequency and the factors associated with transmission of gastrointestinal nematodes and Cryptosporidium sp. in ostriches, 342 faecal samples were collected from 188 adults and 154 young ostriches raised in seven herds in the Regional Pole of Paraguaçu. Samples were evaluated for fecal eggs count, nematodes third-stage larvae and Cryptosporidium sp oocysts frequency. The data related to animals and their environments have been obtained by visiting the properties and interviews with producers. The association between parasite burden and the variables of 
management of the animals was analyzed by chi-square and "Odds ratio", with an interval of $95 \%$. In all flocks were found infected birds. In $88.3 \%$ of stool samples were detected eggs of gastrointestinal nematodes, and $18.8 \%$ Cryptosporidium sp oocysts. Libyostrongylus dentatus (98\%), L.douglassii (2\%) and Codiostomum sp (2\%) larvae were identified in faecal cultures. Environmental and management factors were associated with risk enteric parasites in ostrich farms. It was found that the ostriches kept in paddocks of irregular topography, in the absence of other animals or receiving water coming from wells or cisterns had lower chances of infection by nematodes. As for the Cryptosporidium genus, the creation in flat areas, with the presence of other animals in the paddocks and the supply of river water increases the chances (2.7 times) of infection.

Keywords: birds, coccidian, parasites, ratites, Strongylida, Struthio camelus.

\section{INTRODUÇÃO}

A ocorrência de parasitos em avestruzes tem sido registrada em plantéis no Brasil (BONADIMAN et al., 2006; MOREIRA et al., 2007) e em outros países, como por exemplo, Austrália (MORE, 1996a,b), Grécia (SOTIRAKI et al., 2001), Escócia (PENNYCOTT \& PETTERSON, 2001), Croácia (TISLJAR et al., 2007), Espanha e Portugal (PONCE GORDO et al., 2002). Os helmintos são responsáveis por prejuízos econômicos na estrutiocultura (EDERLI \& OLIVEIRA, 2009; SOTIRAKI et al., 2001; COOPER, 2005). O nematoide do gênero Libyostrongylus é o mais frequente e patogênico e pode ocasionar até $50 \%$ de morte nas aves jovens (HUCHZERMEYER, 2002; MORE, 1996a).

Os protozoários gastrintestinais são também encontrados em avestruzes, embora essas infecções sejam raramente patogênicas (BLACK, 2001; PONCE GORDO et al., 2004, 2008.) O primeiro caso de infecção por Cryptosporidium sp. nessas aves foi descrito por Gajadhar (1993), mas ainda há poucos trabalhos sobre tal parasito em ratitas. A criptosporidose aviária, antes considerada doença oportunística, recentemente, tornou-se evidente que seu significado econômico não pode ser subestimado. Aves parasitadas pelo gênero Cryptosporidium podem apresentar inflamação intestinal e prolapso da cloaca (SANTOS et al., 2005).

Vários fatores podem favorecer a infecção de avestruzes por parasitos, com destaque para os geoambientais, nos quais o clima tropical, a hidrografia, tipo de solo, entre outros, propiciam o desenvolvimento e manutenção de estádios infectantes dos parasitos (PÉREZ CORDÓN et al., 2008). Assim, este estudo foi realizado para verificar a frequência de nematoides gastrintestinais e do protozoário do gênero Cryptosporidium em avestruzes do Polo Regional do Paraguaçu no Estado da Bahia e identificar fatores possivelmente associados à infecção das aves.

\section{MATERIAL E MÉTODOS}

Foram colhidas amostras de fezes de 342 avestruzes African Black, dos quais 188 eram adultos ( 78 reprodutores e 110 matrizes) e 154 jovens (inferior a oito meses de idade) criados em sete plantéis no Polo Regional do Paraguaçu, que incluem cinco municípios com características climáticas diversas, de úmido a seco, altitude de cinco a $283 \mathrm{~m}$, vegetação formada por Floresta estacional semidecidual, caatinga e cerrado, pluviosidade entre 800 e $2.000 \mathrm{~mm}$ anuais e área territorial municipal de 94,36 a $398,47 \mathrm{~km}^{2}$ (BAHIA, 2008).

Os animais eram criados em piquetes, alguns possuíam cobertura forrageira. 
A água fornecida aos animais originavase de poço artesiano/cisterna ou rio, e a alimentação era sustentada pela oferta de ração comercial (Núcleo Guabi) própria para a espécie. Suplementação com leguminosas da região era fornecida aos animais em alguns plantéis.

A amostragem baseou-se no número de plantéis e de avestruzes $(\mathrm{n}=1.588)$ desse Polo Regional, a partir dos registros da Associação Baiana dos Criadores de Avestruz (ABCAV). O tamanho da amostra por propriedade foi calculado em consideração de uma prevalência esperada de $69 \%$, precisão de $5 \%$ e intervalo de confiança de $95 \%$. Para realizar tal procedimento, utilizouse o software Epi Info $6^{\circledR}$.

Entre agosto e novembro de 2007, foi realizada apenas uma coleta de fezes por animal, logo após a eliminação. Utilizaram-se dois gramas de fezes, para a contagem de ovos por grama (OPG), de acordo com Gordon \& Whitlock (1939) e aproximadamente 10 gramas para a coprocultura, para obtenção de larvas de terceiro estádio de nematoides da ordem Strongylida, conforme Robert's \& O'Sullivan (1950). Para a identificação genérica, as larvas foram imersas em solução de hipoclorito de sódio, a $2,5 \%$ por três minutos, para a retirada da bainha e coradas com solução de lugol (BONADIMAN et al., 2006). A identificação específica foi baseada na morfologia das larvas infectantes, descrita por Ederli et al. (2008abc).

Para a pesquisa de oocistos de Cryptosporidium, foram examinadas 154 amostras de fezes, de aves jovens, pela técnica de sedimentação. Os esfregaços fecais foram corados por Ziehl-Neelsen modificada (HENRICKSEN \& POHLENZ, 1981) e examinados por microscopia óptica (400x e 1000x) para a identificação morfológica, conforme Ortolani (2000).

Os dados relacionados aos animais e ao ambiente foram obtidos por meio de visita às propriedades e entrevistas com os produtores através de formulário précodificado. As informações foram analisadas a partir de tabelas de frequência. A associação entre $\mathrm{o}$ parasitismo e as variáveis de manejo dos animais em cada propriedade foi examinada pelo teste Qui-quadrado e por razão de Odds, com intervalo de confiança de $95 \%(\mathrm{p}<0,05)$.

\section{RESULTADOS E DISCUSSÃO}

Em todos os plantéis foram encontradas aves infectadas por parasitos gastrintestinais, e, em 88,3\% (302/342) das amostras de fezes, foram detectados ovos da ordem Strongylida, e, em 18,8\% (29/154), oocistos de Cryptosporidium sp. (Tabela 1).

As principais características dos plantéis confrontadas com o parasitismo foram: categoria das aves, estrutura do piquete, presença de outros animais na propriedade, fonte de água, suplementação com leguminosa, topografia e tratamento anti-helmíntico (Tabela 2).

A avaliação de infecção por parasitos gastrintestinais em avestruzes, por meio de inquéritos parasitológicos, é um parâmetro utilizado para o manejo sanitário de aves que são criadas semiextensivamente em regiões tropicais. No Brasil e em outros países, os estudos sobre a prevalência de nematoides em $S$. camelus são poucos e envolvem um número pequeno de animais. 
Rev. Bras. Saúde Prod. Anim., Salvador, v.13, n.4, p.1054-1065 out./dez., 2012 http://www.rbspa.ufba.br ISSN 15199940

Tabela 1. Frequência de infecção por nematoides da ordem Strongylida e protozoário do gênero Cryptosporidium em plantéis $(\mathrm{P})$ de avestruzes do Polo regional do Paraguaçu, Estado da Bahia

\begin{tabular}{lccrccc}
\hline \multirow{2}{*}{ Plantéis } & \multicolumn{3}{c}{ Ovos de Strongylida } & \multicolumn{3}{c}{ Oocistos de Cryptosporidium sp. } \\
\cline { 2 - 7 } & Total de amostras & Positivos & \multicolumn{1}{c}{$\%$} & Total de amostras & Positivos & $\%$ \\
\hline P1 & 61 & 60 & 98,4 & 27 & 9 & 33,3 \\
P2 & 14 & 14 & 100,0 & - & - & - \\
P3 & 25 & 18 & 72,0 & 7 & 2 & 28,6 \\
P4 & 27 & 27 & 100,0 & 8 & 1 & 12,5 \\
P5 & 70 & 70 & 100,0 & 19 & 2 & 10,5 \\
P6 & 109 & 77 & 70,6 & 75 & 12 & 16,0 \\
P7 & 36 & 36 & 100,0 & 18 & 3 & 16,7 \\
\hline Total & 342 & 302 & 88,3 & 154 & 29 & 18,8 \\
\hline
\end{tabular}

*Inexistência de aves jovens no plantel.

Tabela 2. Frequência de avestruzes criados no Polo Regional do Paraguaçu, Estado da Bahia, infectados por nematoides da ordem Strongylida e por coccídio do gênero Cryptosporidium

\begin{tabular}{|c|c|c|c|c|}
\hline \multirow{2}{*}{ Variáveis Independentes } & \multicolumn{2}{|c|}{ Strongylida } & \multicolumn{2}{|c|}{ Cryptosporidium sp. } \\
\hline & Total & Positivo & Total & Positivo \\
\hline \multicolumn{5}{|l|}{ Categoria } \\
\hline Jovem & $154(45,0)^{*}$ & $118(39,1)$ & $154(100)$ & 18,8 \\
\hline Adulto & $188(55,0)$ & $184(60,9)$ & $\mathrm{ND}^{1}$ & $\mathrm{ND}^{1}$ \\
\hline \multicolumn{5}{|l|}{ Estrutura de Piquete } \\
\hline Com pastagem & $254(74,3)$ & $221(73,2)$ & $128(83,1)$ & $25(86,2)$ \\
\hline Sem pastagem & $88(25,7)$ & $81(26,8)$ & $26(16,9)$ & $4(13,8)$ \\
\hline \multicolumn{5}{|l|}{ Presença de outros animais } \\
\hline Sim & $229(67,0)$ & $197(65,2)$ & $120(77,9)$ & $18(62,1)$ \\
\hline Não & $113(33,0)$ & $105(34,8)$ & $34(22,1)$ & $11(37,9)$ \\
\hline \multicolumn{5}{|l|}{ Fonte de água } \\
\hline Rio & $242(70,8)$ & $210(70,0)$ & $120(77,9)$ & $18(62,1)$ \\
\hline Poço Artesiano/Cisterna & $100(29,2)$ & $92(30,0)$ & $34(22,1)$ & $11(37,9)$ \\
\hline \multicolumn{5}{|c|}{ Suplementação com leguminosa } \\
\hline Não & $240(70,2)$ & $201(66,6)$ & $119(77,3)$ & $19(65,5)$ \\
\hline Sim & $102(29,8)$ & $101(33,4)$ & $35(22,7)$ & $10(34,5)$ \\
\hline \multicolumn{5}{|l|}{ Topografia } \\
\hline Plana & $281(82,2)$ & $242(80,1)$ & $127(82,5)$ & $20(69,0)$ \\
\hline Acidentada & $61(17,8)$ & $60(19,9)$ & $27(17,5)$ & $9(31,0)$ \\
\hline \multicolumn{5}{|l|}{ Tratamento Anti-helmíntico } \\
\hline Não & $25(7,3)$ & $18(6,0)$ & $\mathrm{ND}^{2}$ & $\mathrm{ND}^{2}$ \\
\hline Sim & $317(92,7)$ & $284(94,0)$ & $\mathrm{ND}^{2}$ & $\mathrm{ND}^{2}$ \\
\hline
\end{tabular}


A frequência de avestruzes infectados por nematoides da ordem Strongylida, observada no Polo Regional do Paraguaçu, foi menor do que a observada no Estado do Rio de Janeiro (100\%), por Bonadiman et al. (2006) e superior à encontrada no Rio Grande do Sul (66\%), conforme Moreira et al. (2007). Em relação aos plantéis, neste estudo, em $100 \%$ foram encontradas aves infectadas com NGI, frequência superior à demonstrada por Mukaratirwa et al. (2004), no Zimbábue, no qual o nematoide $L$. douglassii estava presente em $64 \%$ (7/11) dos criatórios. Em 71,4\% dos plantéis (5/7), os avestruzes apresentaram mediana do OPG acima de 1.000 , ao contrário dos resultados de Tisljar et al. (2007), nos quais entre 85,7 e $89,7 \%$ das amostras, os OPG foram menores que 500. Na necropsia de dois animais, numerosos parasitos foram encontrados no proventrículo, onde se detectou hiperplasia de células mononucleares. No entanto, a relação entre o OPG e a carga patogênica não é conhecida para essa ratita.

Diante da distribuição anormal dos dados de OPG, das amostras e inexistência na literatura de valores de referência para a carga parasitária, optou-se por usar a mediana do OPG para comparação dos dados, cujo ponto de corte foi o valor de 700. Nos plantéis $3 ; 1$ e 5, ocorreram as maiores contagens de OPG, respectivamente, 30.800; 18.850 e 17.450. Convém destacar que o plantel 1 teve maior número de animais $(81,9 \%)$ com $\mathrm{OPG}$ acima do ponto de corte, seguido dos plantéis 2; $4 ; 3$ e 5 (Tabela 3). Apenas o plantel 6 diferiu $(\mathrm{p}<0,05)$ dos demais, no qual $82,9 \%$ dos OPG estavam abaixo do ponto de corte, em virtude do tratamento efetuado com ivermectina para controle de artrópodes.

A elevada frequência de amostras positivas para NGI e do número de
OPG nos avestruzes desse Polo Regional podem estar relacionados ao fato das aves ocuparem poucas áreas de pastagem, em uma região que apresenta condições geoambientais favoráveis ao desenvolvimento e à transmissão desses parasitos. Os nematoides de avestruzes, especialmente do gênero Libyostrongylus, estão adaptados ao clima quente e seco, nos quais os ovos permanecem viáveis por até três anos (JANSSON et al., 2002). Estudos sobre fatores predisponentes para infecção por enteroparasitos em avestruzes são escassos. A idade da ave foi associada à infecção por NGI nos criatórios do Polo Regional do Paraguaçu. A mediana dos valores do OPG foi maior nas aves adultas em função do manejo sanitário, especialmente direcionado para minimizar a possibilidade de infecção nos jovens, pela maior suscetibilidade, inerente ao sistema semiextensivo em que são criadas.

Houve correlação positiva entre a presença de infecção por nematoides e as variáveis de manejo e ambientais (Tabela 4). Avestruzes mantidos sem contato com outros animais como cães, gatos, galináceos ou ruminantes $(\mathrm{OR}=4,9$; IC $95 \% \quad 2,8-8,6 ; \mathrm{p}<0,001)$, que consumiam água proveniente de poço artesiano ou cisterna $(\mathrm{OR}=5,5$; IC $95 \% 3,2-9,3 ; \quad \mathrm{p}<0,001)$, recebiam suplementação proteica a base de leguminosas (OR=6,7; IC 95\% 3,8 11,5; $\mathrm{p}<0,001)$ e eram criados em piquetes de topografia acidentada (OR=6,2; IC 95\% 3,1 - 12,4; p<0,001) apresentaram menores chances de infecção por nematoides gastrintestinais. As aves adultas (matrizes e reprodutores) apresentaram a chance 2,6 vezes menor de eliminarem ovos nas fezes do que as aves jovens (cria e recria). 
Tabela 3. Comparação entre a contagem de ovos por grama de fezes (OPG) da ordem Strongylida e as variáveis relacionadas aos avestruzes e ao ambiente

\begin{tabular}{|c|c|c|c|c|}
\hline \multirow{2}{*}{ Variáveis } & \multirow{2}{*}{$\begin{array}{c}\text { Mediana do } \\
\text { OPG }\end{array}$} & \multirow{2}{*}{ Amplitude de variação } & \multicolumn{2}{|c|}{$\mathrm{N}^{\circ}$ amostras de fezes } \\
\hline & & & $\mathrm{OPG}>700$ & $\mathrm{OPG}<700$ \\
\hline \multicolumn{5}{|l|}{ Plantéis } \\
\hline P1 & 1.700 & $0-18.850$ & $50(81,9)$ & $11(18,1)$ \\
\hline $\mathrm{P} 2$ & 1.300 & $300-4.050$ & $11(78.6)$ & $3(21,4)$ \\
\hline P3 & 1.800 & $0-30.800$ & $16(64,0)$ & $9(36,0)$ \\
\hline $\mathrm{P} 4$ & 1.250 & $100-10.450$ & $20(74,1)$ & $7(25,9)$ \\
\hline P5 & 1.000 & $100-17.450$ & $44(62,9)$ & $26(37,1)$ \\
\hline$P 6^{\mathrm{a}}$ & 100 & $0-7.350$ & $12(17,1)$ & $97(82,9)$ \\
\hline $\mathrm{P} 7$ & 650 & $50-9.400$ & $16(44,4)$ & $20(55,6)$ \\
\hline \multicolumn{5}{|l|}{ Categoria } \\
\hline Jovem & 325 & $0-18.850$ & $56(36,4)$ & $98(63,6)$ \\
\hline Adulto & 1.050 & $0-30.800$ & $113(60,1)$ & $75(39,9)$ \\
\hline \multicolumn{5}{|l|}{ Estrutura de Piquete } \\
\hline Com pastagem & 600 & $0-18.850$ & $117(46,1)$ & $137(53,9)$ \\
\hline Sem pastagem & 1.000 & $0-30.800$ & $52(59,1)$ & $36(40,9)$ \\
\hline \multicolumn{5}{|l|}{ Presença de outros animais } \\
\hline Sim & 400 & $0-17.450$ & $83(36,2)$ & $146(63,8)$ \\
\hline Não & 1.650 & $0-30.800$ & $86(76,1)$ & $27(23,9)$ \\
\hline \multicolumn{5}{|l|}{ Fonte de água } \\
\hline Rio & 450 & $0-17.450$ & $92(38,1)$ & $150(61,9)$ \\
\hline Poço Artesiano/Cisterna & 1.675 & $0-30.800$ & $77(77,0)$ & $23(23,0)$ \\
\hline \multicolumn{5}{|c|}{ Suplementação com leguminosa } \\
\hline Não & 425 & $0-30.800$ & $88(36,6)$ & $152(63,4)$ \\
\hline Sim & 1.575 & $0-1.750$ & $81(79,4)$ & $21(20,6)$ \\
\hline \multicolumn{5}{|l|}{ Topografia } \\
\hline Plana & 550 & $0-30.800$ & $119(42,3)$ & $162(57,7)$ \\
\hline Acidentada & 1.700 & $0-18.850$ & $50(81,9)$ & $11(18,1)$ \\
\hline
\end{tabular}


Rev. Bras. Saúde Prod. Anim., Salvador, v.13, n.4, p.1054-1065 out./dez., 2012 http://www.rbspa.ufba.br ISSN 15199940

Tabela 4. Análise de variáveis relacionadas à infecção por nematoides da Ordem Strongylida e coccídio do gênero Cryptosporidium em plantéis de avestruzes criados no Polo Regional do Paraguaçu, Estado da Bahia, 2007

\begin{tabular}{|c|c|c|c|c|}
\hline \multirow[b]{2}{*}{ Variáveis } & \multicolumn{2}{|c|}{ Strongylida } & \multicolumn{2}{|c|}{ Cryptosporidium sp. } \\
\hline & $\begin{array}{l}\text { Razão de } O d d s \\
\quad(\text { IC95\%) }\end{array}$ & $p$ & $\begin{array}{l}\text { Razão de Odds } \\
\quad \text { (IC95\%) }\end{array}$ & $p$ \\
\hline \multicolumn{5}{|c|}{ Categoria } \\
\hline Jovem & Referência & \multirow[b]{2}{*}{0,001} & ND & \multirow[t]{2}{*}{ ND } \\
\hline Adulto & $2,6(1,7-4,1)$ & & & \\
\hline \multicolumn{5}{|l|}{ Estrutura de Piquete } \\
\hline Com pastagem & Referência & & Referência & \\
\hline Sem pastagem & $1,5(0,8-2,5)$ & 0,174 & $0,7(0,2-2,4)$ & 0,622 \\
\hline \multicolumn{5}{|c|}{ Presença de outros animais } \\
\hline Sim & Referência & & Referência & \\
\hline Não & $4,9(2,8-8,6)$ & 0,001 & $2,7(1,1-6,5)$ & 0,022 \\
\hline \multicolumn{5}{|l|}{ Fonte de água } \\
\hline Rio & Referência & & Referência & \\
\hline Poço & $5,5(3,2-9,3)$ & 0,001 & $2,7(1,1-6,5)$ & 0,022 \\
\hline Artesiano/Cisterna & & & & \\
\hline \multicolumn{5}{|c|}{ Suplemento com leguminosa } \\
\hline Não & Referência & & Referência & \\
\hline Sim & $6,7(3,8-11,5)$ & 0,001 & $2,1(0,9-5,1)$ & 0,094 \\
\hline \multicolumn{5}{|c|}{ Topografia } \\
\hline Plana & Referência & & Referência & \\
\hline Acidentada & $6,2(3,1-12,4)$ & 0,001 & $2,7(1,0-6,8)$ & 0,034 \\
\hline
\end{tabular}

Larvas de terceiro estádio $\left(\mathrm{L}_{3}\right)$ do gênero Libyostrongylus foram recuperadas nas culturas de fezes de todos os plantéis, enquanto do gênero Codiostomum foi encontrada em apenas 57\% (4/7). A positividade para larvas de Libyostrongylus sp. foi similar, entre jovens $(99,6 \%)$ e adultos $(98,4 \%)$, e para o gênero Codiostomum as frequências foram de $1,6 \%$ e $0,4 \%$ nos adultos e jovens, respectivamente. As espécies de Libyostrongylus que infectam os avestruzes dos vários plantéis do Polo do Paraguaçu foram L.dentatus $(98 \%)$ e L.douglassii (2\%).

$\mathrm{Na}$ Austrália, a ausência de $L$. douglassii em filhotes, é reflexo da prática de criar adultos separados destes (MORE, 1996ab). Outro aspecto relevante foi à criação dos reprodutores e matrizes em colônias que associada à condições favoráveis para 0 desenvolvimento de estágios de vida livre dos gêneros Libyostrongylus e Codiostomum às condições climáticas da região possibilitou que a infecção acontecesse em todos os membros da colônia. O maior parasitismo de avestruzes adultos no Rio Grande do Sul foi relacionado à umidade e lotação dos piquetes onde estavam alojados (MATTOS et al., 2004). Neste inquérito, constatou-se que não havia um programa de controle de parasitos das aves em todos os plantéis. Isso também foi evidenciado por Mukaratirwa et al. (2004), visto que em 57,1\% (5/7) dos rebanhos no Zimbábue o tratamento 
anti-helmíntico não era frequente. A falta de conhecimento sobre manejo e prevenção de doenças constitui-se em problema para a criação dessas ratitas, especialmente com referência ao controle parasitário (BONADIMAN et al., 2006). Um ponto importante a ressaltar é a ausência de registro de antihelmínticos para uso em avestruzes, o que pode dificultar o controle, uma vez que as populações desses nematoides provavelmente não podem desaparecer apenas por modificações do manejo (JANSSON et al., 2002).

A presença de animais domésticos ou silvestres nas áreas de criação representou um aumento da possibilidade de infecção para os avestruzes, visto poderem eliminar ovos e oocistos e favorecerem uma maior exposição. Como exemplo, o C. baileyi pode infectar uma variedade de aves e deve ser considerado o seu papel na epidemiologia da criptosporidiose aviária (GRAAF et al.,1999).

Demonstrou-se ainda que avestruzes que consumiam uma dieta com leguminosas apresentaram uma chance maior de não se infectar com NGI. Como em outras espécies animais, especialmente ruminantes, foi verificado que independente dos valores de OPG, bezerros com uma dieta proteica a níveis adequados, conseguiam superar melhor os efeitos do parasitismo, quando comparados a bezerros com dieta deficiente e submetidos ao mesmo desafio (GENNARI et al., 1995). No entanto, no estudo de Polat et al. (2004), sobre o efeito de dietas com diferentes níveis proteicos sobre parâmetros produtivos em avestruzes, foi constatado que dietas ricas em proteína não modificaram 0 desempenho zootécnico, nem influenciaram o crescimento e a saúde dessas aves.

A escassez de dados epidemiológicos, especialmente sobre os fatores associados à infecção por parasitos em avestruzes, dificultou, em parte, a análise comparativa dos resultados encontrados neste estudo. Entretanto, demonstrou-se que infecções por enteroparasitos foram comuns em avestruzes no Polo Regional do Paraguaçu, no Estado da Bahia, e a infecção pelo nematoide Libyostrongylus foi mais frequentes em relação ao protozoário Cryptosporidium, o que torna necessária a elaboração de estratégias e medidas de saúde a serem implementadas no controle destes parasitismos.

Com relação à positividade para oocistos de Cryptosporidium e as variáveis estudadas, estrutura de piquete $(\mathrm{OR}=1,05 ;$ IC $95 \% \quad 0,39 \quad-2,88$; $\mathrm{p}=0,925)$ e uso de suplementação leguminosa $(\mathrm{OR}=0,48$; IC 95\% 0,20 1,$14 ; \mathrm{p}=0,092$ ), não se observou associação estatisticamente significativa (Tabela 4). Os resultados apresentados na tabela seguinte mostram que a criação de avestruzes em áreas planas, com presença de outros animais nos piquetes e o fornecimento da água do rio aumentam as chances de infecção por esse protozoário em $62 \%, 55 \%$ e $63 \%$, respectivamente.

Apenas 22 (18,33\%) das amostras fecais dos animais jovens foram positivas para ovos da ordem Strongylida e oocistos do coccídIo, enquanto 32 (80\%) foram negativas para ambos os parasitos.

A observação do parasitismo por Cryptosporidium sp., encontrada neste trabalho, foi alta em avestruzes jovens, apesar destes não terem apresentado sinais clínicos da doença. A infecção por $C$. baileyi tem uma maior frequência em aves jovens, visto as mais velhas desenvolverem uma resposta imune eficiente, sem produzirem sinais clínicos (GRAAF et al.,1999). Embora no presente estudo, o coccídIo não tenha sido investigado nos adultos, estes também são suscetíveis à 
infecção. Como constatado por Gajadhar (1993), a presença de oocistos em $8,5 \%(14 / 165)$ das amostras de fezes de avestruzes adultos, com uma variação de poucos a milhões de oocistos por grama de fezes, podem ser uma fonte de contaminação para os jovens. É importante citar que a tipologia climática do Polo Regional do Paraguaçu influenciou nessa prevalência, por favorecer o desenvolvimento e a sobrevivência dos parasitos.

Outro fator de destaque é a água fornecida aos animais, que pode servir como o modo primário de distribuição de oocistos entre as aves. Nos criadouros, apenas $21,3 \%$ das aves consumia água proveniente de poços artesianos ou cisterna, o que reduziu em $62,9 \%$ a chance de infecção pelo protozoário. Águas subterrâneas, pelo processo de infiltração pelas camadas do solo, apresentam menor quantidade de oocistos do que os mananciais superficiais. Não há relato de nenhum oocisto recuperado a $70 \mathrm{~cm}$ de profundidade do solo (FAYER et al., 2000). De fato, os animais estão mais sujeitos ao parasitismo por Cryptosporidium quando expostos à água de rio, devido ao poder da disseminação hídrica. A detecção frequente de oocistos deste coccídio na água de mananciais superficiais, em virtude de atividades agropecuárias e antrópicas, como ocupação urbana (DIAS et al., 2008). Esse evento sinaliza para outro problema, pois, algumas espécies como o $C$. meleagridis podem infectar o homem, especialmente os imunocompetentes (CAMA et al., 2003).

Existem duas espécies de Cryptosporidium que parasitam avestruzes no Brasil, uma similar a $C$. baileyi (SANTOS et al., 2005) e um novo isolado, denominado OstrichBR-
01 (MEIRELES et al., 2006), porém no presente inquérito não foi realizada a identificação específica. Uma associação positiva foi encontrada entre a criação das aves em chão batido e plano com a infecção por Cryptosporidium, explicada, talvez, pelos hábitos da ciscagem e coprofagia, dificultados em piquetes coberto com gramíneas e ainda pela a topografia plana, que afeta a condução das águas pluviais e pode propiciar o desenvolvimento e manutenção de enteroparasitos.

\section{REFERÊNCIAS}

BAHIA. Superintendência de Estudos Econômicos e Sociais da Bahia.

Informações Geoambientais.

Disponível em

<http://www.sei.ba.gov.br>. Acesso em 03 de março de 2008.

BLACK, D.B.V.S. Ostrich Flock Health. Seminars in avian and exotic pet medicine, v.10, n.3, p.117-130, 2001.

BONADIMAN, S.F.; EDERLI, N.B.; SOARRES, A.K.P.; MORAES NETO, A.H.A.; SANTOS, C.P.; DaMATTA, R.A. Occurrence of Libyostrongylus sp (Nematoda) in ostriches (Struthio camelus Linnaeus, 1758) from the north region of the state of Rio de Janeiro, Brazil. Veterinary Parasitology, v.137, p.175-179, 2006.

CAMA, V.A.; BERN, C.; SULAIMAN, I.M.; GILMAN, R.H.; TICONA, E.; VIVAR, A.; KAWAI, V.; VARGAS, D.; ZHOU, L.; XIAO, L.

Cryptosporidium species and genotypes in HIV-Positive patients in Lima, Peru. Journal of Eukaryotic Microbiology, v.50, n.6, p.531-533, 2003. 
Rev. Bras. Saúde Prod. Anim., Salvador, v.13, n.4, p.1054-1065 out./dez., 2012 http://www.rbspa.ufba.br ISSN 15199940

COOPER, R.G. Bacterial, fungal and parasitic infections in the ostrich (Sruthio camelus var. Domesticus). Animal Science Journal, v.76, p.97106, 2005.

DIAS, G.M.F.; BEVILACQUA, P.D.; BASTOS, R.K.X.; OLIVEIRA, A.A.; CAMPOS, G.M.M. Giardia spp e Cryptosporidium spp em água de manancial superficial de abastecimento contaminada por dejetos humano e animal. Arquivo Brasileiro de Medicina Veterinária e Zootecnia, v.60, n.6, p.1291-1300, 2008.

EDERLI, N.B.; OLIVEIRA, F.C.R. Differential Localization of Libyostrongylus douglassii (Cobbold, 1882) Lane, 1923 and L. dentatus (Nematoda: Trichostrongylidae) in Ostrich (Struthio camelus Linnaeus, 1758) Proventriculi. Journal of Parasitology, v.95, n.3, p.757-759, 2009.

EDERLI, N.B.; OLIVEIRA, F.C.R.; LOPES, C.W.G.; DaMATTA, R.A.; SANTOS, C.P.; RODRIGUES, M.L.A. Morphological diagnosis of infective larvae of Libyostrongylus douglassii (Cobbold, 1882) Lane, 1923 and $L$. dentatus Holberg, Lloyd and Omar, 1995 (Nematoda: Trichostrongylidae) of ostriches. Veterinary Parasitology, v.155, p.323-327, 2008a.

EDERLI, N.B.; BONADIMAN, S.F.; MORAES NETO, A.H.A.; DaMATTA, R.A.; SANTOS, C.P. Mixed infection by Libyostrongylus douglassii and $L$. dentatus (Nematoda:

Trichostrongylidae) in Struthio camelus (Ratites: Struthioniformes) from Brazil with further morphological characterization of adults. Veterinary Parasitology, v.151, p.227-232, 2008b.
EDERLI, N.B.; OLIVEIRA, F.C.R.; RODRIGUES, M.L.A. Futher study of Codiostomum struthionis (Horst, 1885) Railliet and Henry, 1911 (Nematoda, Strongylidae) parasite of ostriches (Struthio camelus Linnaeus, 1758) (Aves, Struthioniformes). Veterinary Parasitology, v.157, p.275-283, 2008c.

FAYER, R.; MORGAN, U.; UPTON, S.J.; Epidemiology of Cryptosporidium: transmission, detection and identification. Internation Journal for Parasitology, v.30, p.1305-1322, 2000.

GAJADHAR, A.A. Cryptosporidium species in imported ostriches and consideration of possible implications for birds in Canada. Canadian.

Veterinary Journal, v.34, p.115-116, 1993.

GENNARI, S.M.; ABDALLA, A.L.; VITTI, D.M.S.S.; MEIRELLES, C.F.; LOPES, R.S.; VIEIRA BRESSAN, M.C.R. Haemonchus placei in calves: effects of dietary protein and multiple experimental infection on worm establishment and pathogenesis.

Veterinary Parasitology, v.59, n.2, p.119-126, 1995.

GORDON, N.M.; WITHLOCK, H.V . A new technique for counting nematode eggs in sheep faeces. Journal of the Council for Scientific and Industrial Research, v.12, p.50-52, 1939.

GRAAF, D.C.; VANOPDENBOSCH, E.; ORTEGA-MORA, L.M.; ABBASSI, H.; PEETERS. A review of the importance of cryptosporidiosis in farm animals. International Journal for Parasitology, v.20, p.1269-1287, 1999. 
Rev. Bras. Saúde Prod. Anim., Salvador, v.13, n.4, p.1054-1065 out./dez., 2012 http://www.rbspa.ufba.br ISSN 15199940

HENRICKSEN, S.A.; POHLENZ, J.F.L. Staining of cryptosporidia by modified Ziehl-Neelsen technique. Acta Veterinaria Scandinavia, v.22, p.594596, 1981.

HUCHZERMEYER, F.W. Diseases of farmed crocodiles and ostriches. Revue Scientific Technique (International Office of Epizootics), v.21, p.265-276, 2002.

JANSSON, D.S.; CHRISTENSSON, C.A.; CHRISTENSSON, B.E. Winter survival in Sweden of $\mathrm{L}_{3}$-Stage larvae of the ostrich wireworm

Libyostrongylus douglassii. Veterinary

Parasitology, v.106, p.69-74, 2002.

MATTOS, M.J.T.; RIBEIRO, M.;

DALMAGRO, M.; BIANCO JUNIOR, A.; SCOPELI, C.; SEIBERT, M.;

PRAETZEL, K. Ocorrência de ovos de helmintos em avestruzes mantidos em cativeiro na grande Porto Alegre-RS.

Revista Brasileira de Parasitologia Veterinária, v.13, p.253, 2004. Supl. 1.

MEIRELES, M.V.; SOARES, R.M.; SANTOS, M.M.A.B.; GENNARI, S.M. Biological studies and molecular characterization of a Cryptosporidium isolate from ostriches (Struthio camelus). Journal of Parasitology, v.92, n.3, p.623-626, 2006.

MORE, S.J. The performance of farmed ostrich chicks in eastern Australia.

Preventive Veterinary Medicine, v.29, p.91 - 106, 1996a.

MORE, S. J. The performance of farmed ostrich hens in eastern Australia. Preventive Veterinary Medicine, v.29, p.107-120, 1996b.
MOREIRA, P.V.; CHIMINAZZO, C.; QUEIROLO, M.T.; FESER, M.; CERESER, V.H.; ESMERALDINO, A.T.; DIFINI, R.; FALLAVENA, L.C.B. Ventriculite parasitária por Libyostrongylus sp em avestruz (Struthio camelus) e identificação de ovos do parasita em amostras de fezes de ratitas de diferentes criatórios do Estado do Rio Grande do Sul.

Veterinária em Foco, v.4, n.2, p.169176, 2007.

MUKARATIRWA, S.; CINDZI, Z.M.; MAONONGA, D.B. Prevalence of libyostrongylus douglassii in commercialy reared ostriches in the highveld region of Zimbabwe. Journal of Helminthology, v.78, p.333-336, 2004.

ORTOLONI, E.L. Standardization of the modified Ziehl-Neelsen technique to stain oocists of Cryptosporidium.

Revista Brasileira de Parasitologia

Veterinária, v.9, n.1, p.29-31, 2000.

PENNICOTT, T.; PETERSSON, T. Gastrointestinal parasites in ostrich (Struthio camelus). Veterinary Records, v.148, p.156, 2001.

PÉREZ CORDÓN, G.; HITOS PRADOS, A.; ROMERO, D.; SÁNCHEZ MORENO, M.; PONTES, A.; OSUNA, A.; ROSALES, M. J. Intestinal parasitism in the animals zoological garden "Peña Escrita" (Almuñecar, Spain). Veterinary Parasitology, v.156, p.302-309, 2008.

POLAT, U.; CETIN, M.; AK, I.; BALCI, F. Detection of serum protein fractions and their concentrations in laying and non-laying ostriches (Struthio camelus) fed with different dietary protein levels. Revue de Medecine Veterinaire, v.155, n.11, p.570-574, 2004. 
Rev. Bras. Saúde Prod. Anim., Salvador, v.13, n.4, p.1054-1065 out./dez., 2012 http://www.rbspa.ufba.br ISSN 15199940

PONCE GORDO, F.; HERRERA, S.; CASTRO, A.T.; GARCÍA DURÁN, B.; MARTÍNEZ DÍAZ, R.A. Parasites from farmed ostriches (Struthio camelus) and Rheas (Rhea americana) in Europe. Veterinary Parasitology, v.107, p.137-160, 2002.

PONCE GORDO, F.; MARTÍNEZ DÍAZ, R.A.; HERRERA, S. Entamoeba struthionis n.sp. (Sarcomastigophora: Endamoebidae) from ostriches (Struthio camelus). Veterinary Parasitology, v.119, p.327-335, 2004.

PONCE GORDO, F.; JIMENEZ-RUIZ, E.; MARTÍNEZ-DÍAZ, R.A. Tentative identification of the species of Balantidium from ostriches (Struthio camelus) as balantidium coli-Like by analysis of polymorphic DNA.

Veterinary Parasitology, v.157, p.4149, 2008.

ROBERTS, F.H.S.; O'SULLIVAN, P.J. Methods for egg counts and larval cultures for strongyles infecting the gastrointestinal tract of cattle. Australian Journal of Agricultural Research, v.1, n.1, p.99-102, 1950.
SANTOS, M.M.A.B.; PEIRÓ, J.R.; MEIRELES, M.V. Cryptosporidium infection in ostriches (Struthio camelus) in Brazil: Clinical, Morphological and Molecular Studies. Brazilian Journal of Poultry Science, v.7, n.2, p.113-117, 2005.

SOTIRAKI, S.T.; GEORGIADES, G.; ANTONIADOU-SOTIRIADOU, K.; HIMONAS, C.A. Gastrointestinal parasites in ostriches. Veterinary journal, v.20, p.84-86, 2001.

TISLJAR, M.; BECK, R.; COOPER, R.G.; MARINCULIC, A.; TUDJA, M.; LUKAC-NOVAK, I.; GRABAREVIC, Z.; HERAK-PERKOVIC, V.; SIMPRAGA, B. First finding of Libyostrongylosis in farm-reared ostrich (Struthio camelus) in Croatia: Unusual histopathological fiding in the braim of two ostriches, naturally infected with Libyostringylus douglasi. Veterinary Parasitology, v.147, p.118-124, 2007.

Data de recebimento: 14/09/2011

Data de aprovação: 05/10/2012 